\title{
REDUCTION OF CUMULATIVE NUTRITIONAL DEFICIT AND IMPROVEMENT OF EARLY GROWTH IN EXTREMELY PRETERM INFANTS
}

\author{
T. Senterre, J. Rigo \\ University of Liège, Liège, Belgium
}

Background and aims: Insufficient nutrition after birth in very preterm infants leads to major cumulative nutritional deficit that is difficult to overcome and is associated with poor growth and adverse neurolodevelopmental outcomes. The aim of this study was to evaluate cumulative nutritional deficit in $<30$ weeks infants receiving early "aggressive" nutrition to reach rapidly $120 \mathrm{kcal} / \mathrm{kg} *$ day with $3.8 \mathrm{~g} / \mathrm{kg} *$ day of protein as recently recommended.

Methods: A prospective non randomized observational study was realized during first 6 weeks of life in extremely preterm (EPT, $<28$ weeks) and very preterm (VPT, 28-30 weeks) infants during a 2 years period. Cumulative nutritional deficit and subsequent growth of were analyzed.

Results: 91 infants were included during a 2 years period. After 2 weeks of age, cumulative nutritional deficit was $-322 \pm 146$ and $-276 \pm 173 \mathrm{kcal} / \mathrm{kg}$ in EPT and VPT infants respectively $(\mathrm{p}=0.19)$ and $-3.6 \pm 4.6$ and $-4.1 \pm 4.8 \mathrm{~g} / \mathrm{kg}$ of protein $(\mathrm{p}=0.65)$. After 6 weeks, cumulative deficit remained significant only for energy in EPT infants $(-184 \pm 373 \mathrm{kcal} / \mathrm{kg}, \mathrm{p}<0.01)$ corresponding to $3.6 \%$ of the cumulative reference energy intake $(5040 \mathrm{kcal} / \mathrm{kg})$. Reduction of nutritional deficit was associated with higher weight gain and limited postnatal growth restriction.

Conclusion: Early aggressive nutrition in very preterm infants allows a reduction of cumulative nutritional deficit and improved growth during first weeks of life. Improvement was also observed in EPT infants. Long term effects should be evaluated. 